\title{
Helping to Improve the Mental Health of Canadians
}

\author{
Honourable Ginette Petitpas Taylor \\ Minister of Health
}

Last August, when Prime Minister Trudeau asked me to serve as Canada's health minister, I was honoured to continue our government's work to strengthen our publicly funded, universal healthcare system. As a social worker, I had dedicated 25 years to working in the community and helping first responders in their daily work, which included interacting with citizens facing mental health challenges.

My personal experience showed me that when it comes to mental health, Canadians face enormous challenges. Approximately one in three Canadians (more than 9 million people) will be affected by a mental illness during their lifetime. More than 10 Canadians die by suicide each day. And one in three Canadians report having experienced some form of maltreatment as a child, including physical abuse, sexual abuse or exposure to violence at home. In fact, family violence accounts for more than a quarter of violent crimes reported to police.

Mental health issues affect not only individuals and families, but communities and society overall. The economic impacts associated with mental illnesses in Canada are substantial, upwards of $\$ 50$ billion in direct costs (e.g., hospital care, physician care, and drug expenditures) and indirect costs (e.g., loss of productivity, income and health-related quality of life).

These facts are a reminder to all of us of the work that remains - work that cannot be done alone by any one government department or agency, charitable group, or private organization.

\section{INCREASING ACCESS TO MENTAL HEALTH SERVICES}

Our government has taken significant steps to improve the mental health of Canadians. We have reached an agreement with all provinces and territories that will see historic investments in mental health over the next 10 years, which commits $\$ 5$ billion of new, targeted funding to improving access to mental health and addiction services across Canada. This is the first time that such a significant investment has been dedicated to mental health.

Last August, the federal government, and the provinces and territories endorsed a Common Statement of Principles on Shared Health Priorities, which sets out key areas of action, including mental health and addictions, to ensure healthcare systems continue to respond to the needs of Canadians.

I look forward to finalizing bilateral agreements between our government and each of the provinces and territories, such as I recently announced with my home province of New Brunswick. We will work with each of the provinces and territories to confirm how they will invest federal funding in their jurisdiction. To 
provide Canadians with concrete information on how these funds are improving mental health services in our communities, the Canadian Institute for Health Information is leading a process with the federal, provincial, and territorial governments to establish a set of meaningful indicators that will measure our success.

Improving access to mental health services is just one part of the solution. We must also address the impact of social determinants of health on Canadians' mental health.

\section{SOCIAL DETERMINANTS OF HEALTH}

We know that health, including mental health, is influenced by a number of social, economic, and environmental factors. These can include housing, education, access to employment, sexual orientation, and ethnic background. For example, Canadian adults with less than a high school education report low perceived mental health three times more often than those with a university degree. Evidence indicates that interventions are most effective when considering the unique needs and circumstances of different population groups and communities.

Our government understands the importance of reducing poverty, enhancing early learning and child care, and increasing access to housing, which would contribute to improving the mental health of Canadians. To this end, we are committed to developing a Canadian Poverty Reduction Strategy, to reduce poverty and improve the economic well-being of all Canadians so that they can have a real and fair chance to succeed.

In November of last year, Prime Minister Trudeau announced Canada's first ever National Housing Strategy - a 10-year, \$40-billion plan that will give more Canadians a place to call home. The primary focus of the Strategy will be meeting the needs of Canadians, including seniors, women, and children fleeing family violence; Indigenous peoples; persons with disabilities; those dealing with mental health and addiction issues; veterans; and young adults.

In 2016, our government also introduced the Canada Child Benefit, which provides support to those who need it most, such as single-parent and low-income families. One year later, with the help of this initiative, nearly 300,000 fewer children lived below the poverty line. We continue to work with provinces and territories, the private sector, and educational institutions to explore new approaches to skills development and innovation.

We also support a range of programs and activities that focus on the factors that lead to positive mental health. For example, maternal and child health programs help build resilience in vulnerable children and families by supporting positive parenting, family attachment, and healthy relationships. Many of these programs emphasize cultural literacy and support for Indigenous women, children, and families.

While these are important steps, we know that we must continue to invest in other areas in pursuit of social equity, such as social inclusion and the reduction of discrimination.

\section{SUPPORTS FOR INDIGENOUS PEOPLES}

Nowhere is the need for social equity more urgent than in Canada's Indigenous communities. The harsh reality - and one that must change - is that Canada's Indigenous populations experience undeniable gaps 
in health and mental health outcomes compared to non-Indigenous Canadians. For this, the Crown must bear a large measure of responsibility. Indigenous peoples have suffered from both negligence and systemic discrimination, including in their access to healthcare.

This reality has been made worse by poor housing conditions, unemployment, lack of education and community infrastructure, and the legacy of residential schools. Combined, these factors have significantly impacted mental health outcomes in these communities.

Indigenous youth die by suicide much more often than non-Indigenous youth. To begin to reverse this legacy of neglect and discrimination, Budget 2017 committed \$828 million in new investments to improving the health outcomes of First Nations and Inuit.

As well, the prime minister's recent decision to create two new departments to better respond to Indigenous issues demonstrates our government's resolve to move beyond the structures and institutions of the past that have characterized our relationships with Indigenous peoples.

As part of this historic shift in focus, my predecessor, the Honourable Jane Philpott, has been called upon to improve service delivery and reduce the unacceptable health and social inequalities that Indigenous communities face. I look forward to continuing to work with her in her role as minister of Indigenous services to deliver on the promise to improve the living conditions of First Nations, Inuit, and Métis peoples in Canada.

In addition to the yearly investments to fund programs and services to improve mental health for First Nations and Inuit, our government announced an additional \$69 million over three years to support enhanced access to mental health wellness teams, capacity building for community-based workers, the implementation of the National Inuit Suicide Prevention Strategy, and access to the toll-free First Nations and Inuit Hope for Wellness Help Line, a 24/7 service that can be reached at 1-855-242-3310.

Also, in Budget 2017, the government pledged an additional \$204.2 million to support First Nations and Inuit mental health, including targeted funding for youth suicide prevention and $\$ 86$ million for the NonInsured Health Benefits Program to expand access to mental health professionals and traditional healers to address mental health needs. These significant investments build on existing programming within my own Health Portfolio dedicated to promoting mental health among Indigenous populations.

While these programs and new investments are an important part of our efforts to redress inequities that have impacted Indigenous peoples for generations, we know that much more needs to be done.

\section{REDUCING STIGMA}

One final area where we must improve is in eliminating the stigma associated with mental illness notwithstanding the enormous change in Canadians' views over the past decade. Stigma is a barrier that discourages people from seeking help or from offering support to someone in need.

We would never say to a friend or loved one that they need to "just get over it" if diagnosed with cancer or another disease affecting physical health. So why would it be okay to use that kind of language with someone facing depression, post-traumatic stress disorder, or suicidal thoughts? 
As others have said, a mental health disorder is an illness, not a weakness. We need to go beyond the health sector to promote mental health in schools, workplaces, and communities across Canada.

I look forward to working with partners such as the Canadian Mental Health Association to shine a light on mental illness, face these challenges head on, and help provide hope and recovery to millions of Canadians. 